$\mathrm{Y}, \mathrm{AK} 32.01$

ББК 66.04

DOI 10.22394/1682-2358-2017-4-85-93

V.I. Maly, Doctor of Sciences (Sociology), Head of the Corporate Economy Department, Povolzbsky Institute of Management named after P.A. Stolypin, Branch of the Russian Presidential Academy of National Economy and Public Administration

V.V. Gusev, Candidate of Sciences (Economics), Docent of the Corporate Economy Department, Povolzhsky Institute of Management named after P.A. Stolypin, Branch of the Russian Presidential Academy of National Economy and Public Administration

\section{THE POLITICAL}

\section{AND ECONOMIC ELITE OF MODERN RUSSIA: EVOLUTION AND RECRUITMENT}

The Russian managerial class, the Russian elite and the trends of its development, the mechanisms of its formation and recruitment of new members are considered. A comparative analysis of the mechanism of recruitment of the elite in tsarist Russia, during the Soviet era, and in modern Russia is drawn. The processes of development of the colonial elite in Russia in the 1990s and the policy of nationalization of the elite, which has been conducted by the Federal government in recent years, are studied.

Key words and word-combinations: elite, counter-elite, near-elite environment, cronyism, recruiting, nationalization of the elite.
В.И. Мальй, доктор сочиологиеских наук, заведуюший кафедрой корпоративной экономики Поволжского института упраһления имени П.А. Стольпинна - филиала Российской академии народного хозяйства и государственной службъг при Президенте РФ (email: sreda@email.ru)

В.В. ГусеВ, кандидат экономических наук, доцент кафедри корпоративной экономики Поволжского института упраһления имени П.А. Стольпина - филиала Российской академии народного хозяйства и государственной службы при Президенте РФ (email:vladgus2006@yandex.ru)

\section{ПОАИТИЧЕСКАЯ \\ И ЭКОНОМИЧЕСКАЯ ЭАИТА СОВРЕМЕННОЙ РОССИИ: ЭВОАЮЦИЯ И РЕКРУТИРОВАНИЕ}

Аннотация. Рассматривается российский управленческий класс, российская элита и тенденции ее развития, механизмы формирования и рекрутирования новых членов. Проводится сравнительный анализ механизма рекрутирования в элиту в царской России, во времена СССР и в современной России. Исследуются процессы развития колониальной элиты в Российской Федерации в 1990-е годы и политики национализации элиты, которую в последние годы проводит федеральная власть.

Ключевые слова и словосочетания: элита, контрэлита, околоэлитное окружение, клановость, рекрутирование, национализация элиты.

C осийского обцества российкого общества и отечественного правящего киасса отличается сложностью, противоречиями и характеризуется Авумя 
тенденциями. Во-первых, Аоминирующий управленческий правящий класс и обслуживающие его силы в определенной степени оторваны от российского общества, самоизолированы, в определенной степени добровольно противопоставцены остацьным российским гражданам, часто закрыты дия проникновения новых чиенов - «чужаков». Подобная кастовость правящего класса (господствующего класса, согласно определению К. Маркса [1] ) объясняется непростой экономической и политической ситуацией, в которой оказалась Российская Федерация в последние годы. Именно поэтому Президент РФ и Аругие системообразующие политические фигуры вынуждены опираться на военных и выходџев из правоохранительных структур. Во-вторых, поскольку представители российского традиционного большинства, и особенно креативных слоев общества, так называемые активные граждане или средний класс, часто не могут пробиться в правящие круги, в российскую элиту, многие интемлектуально одаренные мичности, способные к творческому мышлению, развитию и инновациям, эмигрируют из России в более развитые государства, пытаются найти себя на просторах Западной Европы и США, работают в Силиконовой долине, Аондон-Сити, Милане, Гамбурге. Среди тех представителей второй группы, кто по размичным причинам не смог уехать за границу, господствует точка зрения, что это необходимо сделать как можно скорее. Молчаливый протест среднего класса не всегда был пассивным, недовольство существующим положением вещей выплеснулось массовыми акциями осенью-весной 2011-2012 гг. [2], оАнако в Аальнейшем протесты постепенно сошии к минимуму, и в этом во многом заслуга Аействующей власти, своевременно ограничившей недовольных и переведшей протест в мирное русло.

Межжу первой и второй группами, правящим классам и активными гражАанами, существуют взаимосвязи, контакты и точки соприкосновения. Например, нередко представители правящего класса стремятся к тому, чтобы их дети остались на постоянное место жительства в более развитых странах - в Европейском Союзе, США, Великобритании или Швейцарии, и это также свидетельствует о том, что они «с трудом» верят в «светлое российское» будущее, существующее в многочисленных разработках и прогнозах приближенных к власти экономистов и соџиологов. При этом, отправцяя собственных Аетей на учебу за границу, преимущественно в Европу и США, и тем самым способствуя эмиграции, российские чиновники и бизнесмены не надеются на их попадание в западную элиту, на интеграцию с представителями правящих классов, так как это просто невозможно в силу династических традиџий западных правящих кругов. История многих аристократических семей США и Европы насчитывает несколько столетий, поэтому они не воспринимают разбогатевших в ходе реформ 1990-х годов россиян как равных. Будущая благополучная жкизнь потомства современных чиновников, как правило, обеспечивается среАствами, выведенными из России за границу во время нахождения у политической или финансовой власти государства. Проблемам развития действующего правящего класса, противоречиям в этом развитии, особенностям рекрутирования в российскую элиту новых чценов посвящена данная статья.

Прежде всего обратимся к понятию элиты как управмяющего кцасса. ЭАи- 
та (от мат. eligo, англ., фр. elite - избранный, мучший) - совокупность Аюдей, занимающих высокие посты в управлении государством и экономикой. Современная элита представмяет собой устойчивую общность с глубокими взаимосвязями входящих в нее мюдей, имеющих общие интересы и доступ к рычагам реальной власти. Эмита той или иной страны осуществляет основные функции по управлению государством, обществом, соџиамьными институтами. Эките страны противостоит контрэлита - совокупность представитекей оппозиционных политических сил, тайных обществ, теневых кабинетов, авторитетных представителей интемигентских кругов, ученой общественности. Как у элиты, так и у контрэлиты есть так называемое околоэлитное окружение - помошники, советники, начальники охраны, политические обозреватели, консультанты, реАакторы газет, цечащие врачи, родственники [3]. К «окружению» можно отнести и выдающихся спортсменов, артистов, представителей шоу-бизнеса.

Рассмотрим варианты рекрутирования индивидуумов в отечественную элиту в российской парадигме, учитывая традиџии различной степени авторитарного управления государством на протяжении длительных промежутков времени, а также тот факт, что отношение традиционного большинства населения является наиболее уважительным именно к авторитарным, сильным руководителям, например, Ивану Грозному, Петру Первому, И.В. Сталину (табц. 1).

Таблица 1

Варианты рекрутирования новых членов в российскую политическую и экономическую эмиту (сравнитекьный анализ)

\begin{tabular}{|c|c|c|c|}
\hline Страна & Царская Россия & $\mathrm{CCCP}$ & $\begin{array}{c}\text { Современная } \\
\text { Россия }\end{array}$ \\
\hline Входные барьеры & Высокие & Средние & Высокие \\
\hline $\begin{array}{l}\text { Критерий } \\
\text { попадания в элиту }\end{array}$ & $\begin{array}{l}\text { Происхождение - } \\
\text { аристократическое }\end{array}$ & $\begin{array}{l}\text { Происхождение - } \\
\text { пролетарское }\end{array}$ & $\begin{array}{l}\text { Принадлежность } \\
\text { к силовому блоку } \\
\text { и непотизм }\end{array}$ \\
\hline $\begin{array}{l}\text { Партийная } \\
\text { принадлежность }\end{array}$ & Играет среднюю роль & $\begin{array}{l}\text { Играет высокую } \\
\text { роль }\end{array}$ & $\begin{array}{l}\text { Играет высокую } \\
\text { роль }\end{array}$ \\
\hline Роль образования & Высокая & Высокая & Средняя \\
\hline $\begin{array}{l}\text { Замкнутость } \\
\text { (оторванность } \\
\text { от населения) }\end{array}$ & Высокая & Средняя & Высокая \\
\hline Патриотизм & Высокий & Высокий & Средний \\
\hline $\begin{array}{l}\text { Наличие } \\
\text { зарубежных активов }\end{array}$ & Имеется & Не имеется & Имеется \\
\hline Пассионарность & Высокая & Высокая & Средняя \\
\hline $\begin{array}{l}\text { Степень связи } \\
\text { с международными } \\
\text { элитами }\end{array}$ & Высокая & Низкая & Средняя \\
\hline
\end{tabular}


Обратим внимание на изолированность, оторванность российской элиты от общества. Социальные барьеры царской России искусственно создава$\Lambda$ препоны к близости правящих кругов и населения, преимушественно крестьянского. В СССР элита была наиболее близка к народу в силу построения нового обшества, открытости соџиальных кифтов и народного характера элиты, корыстные интересы которой ограничивались Коммунистической партией. Тем не менее на излете существования СССР советская элита также «окукцилась», замкнулась в себе, не прочувствовала вектор грядущих российских перемен, поэтому в ходе быстрых революџионных изменений начала 1990-х годов народ ее в целом не поддержал, что привело к смене государственного строя и развалу единой страны. Современная же, постсоветская, элита изначально взяла курс на изомяџию от общества, на собственное позиџионирование как на обособленный политический класс, клановость, «новое Аворянство», в результате появицся тезис о российском народе как о неполноценном, малообразованном и немобильном [4, с. 30], а то и о существовании двух отдельных народов внутри Российской Федерации - по выражению доктора философских наук, помощника министра культуры РФ А.М. Буровского, «русских европейцев» и «русских туземџев» («туземџев из Московии») [5, с. 157]. А.М. Буровский обвиняет «русских туземцев» в организаџии революџий 1917 года: «Гораздо больший проџент крестьян воевать не хотели и только терпели призыв, и то, пока армия побеждала. Русские туземџы сопротивляются войне то пассивно, всячески укАоняясь от призыва, а потом бегут от воинской повинности, и наконец, доведенные до крайности, бросаются на русских европейцев. В начале 1917 года толпы дезертиров хлынули с фронта. Тогда же в Петербурге произошка Февральская революџия, опиравшаяся на части, которые не хотели попасть на фронт» [5, c. $10-11]$.

Тезис о народе как безвольной, неполноценной массе удобен многим представителям российской элиты, так как оправдывает ее автономное существование, колониальный характер и ориентацию на западные ценности. ОАнако он, в свою очередь, также порождает отчуждение народа от

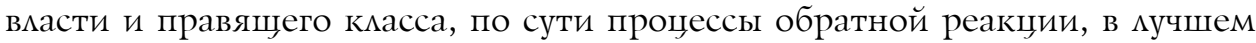
случае это - апатия, саботаж, непринятие вцастных иниџиатив, пассивный протест, в худшем - $ю$ юи пускаются во все тяжкие, к деградаџии, инстинктивным и порочным действиям, и в результате Российская Федерация помучает такое обшество («не из цичностей»), с которым ни оАну сколь- иббо значимую задачу - модернизация, инновации, демографическая проблема, освоение отдаленных территорий, выход страны из кризиса - не решишь $[4$, c. 31$]$.

Аналогичные воззрения, деление на «лучших» и «худших», «доноров» и «реципиентов», «своих» и «чужих», наблюдались в Советском Союзе в конце 1980-х годов, и это закончилось развалом единого государства, делением на «национальные квартиры», повсеместными военными конфликтами (ПриАнестровье, Чечня, Карабах, Абхазия и Южная Осетия, современная Украина), «ползучим» геноџидом, разделением, изгнанием со своей территории других 
национальностей, расколом этнических русских на живущих в Российской Федерации и новых государствах, образовавшихся после распада СССР. По этому поводу 29 сентября 2015 г. в интервью американскому каналу СBS высказался Президент России В.В. Путин: «Я действительно сказал, что считаю распад Советского Союза огромной трагедией XX века. В одночасье за границами Российской ФеАерации оказались 25 мимиионов русских мюдей. Они жици в рамках единого государства, и всегда традиционно Советский Союз назывался Россией, Советской Россией, но это и была большая Россия. Потом неожиданно состоялся развац Советского Союза за ночь, по сути, и оказалось, что в бывших респубциках Советского Союза проживают цюАи, русские люди, в количестве 25 мимиионов человек. Они жили в единой стране - и вАруг оказались за граниџей... Русские оказались сегодня самой большой разделенной нацией в мире» [6] .

В настоящее время речь идет о «западничестве», колониальном характере значительной части российской элиты, отождествцяющей себя с развитым миром, а не с Россией. ОАнако ориентированным на ЗапаА представителям элиты остро ответил выдающийся российский социолог и философ А.А. Зиновьев: «Как бы русские ни опмевывали коммунистический период своей истории, как бы ни усердствовали в разрушении всего того, что бымо Аостигнуто за этот период... как бы ни подражкали всему западному и как бы ни перенимали все пороки Запада, Россия все равно никогда не станет частью Запада. Какая судьба ожидает ее в сфере западнизации, об этом в свое время откровенно сказал и показал Гитлер. Сейчас, разумеется, об этом не говорят вслух, но стремятся делать по сути то же самое. Нужно быть круглым идиотом, чтобы воображать, будто на Западе стали бы млеть от восторга, если бы на мировых рынках появицись мощные конкуренты из России и стали бы вытеснять американских и западноевропейских преАпринимателей» [7] .

Сегодня видна и обратная тенденция: в противовес колониальному мышмению правящего класса в стране осуществляется планомерная работа наА национацизацией элиты, которую проводит федеральная власть. Часть элиты и околоэлитного окружения в настоящее время предлагает высшей российской вмасти искать ацьтернативу миберацьно-рыночному пути развития, так как полагает, что этот путь не предусматривает патернацизма, соџиацьной справедиивости, сплоченности и в целом губителен как Аля общества, так и Аля Российского государства. Все эти вопросы, глобального развития и социацьного мировоззрения, зависят от одного актора - Президента Российской Федерации.

Безусловно, путь национализации элиты и сплочения (скреп) российского общества очень сложен. На наш взгляд, в области Аостижения Аанных Авух целей возможен следующий алгоритм действий. Во-первых, необходимо избавиться от клановости, политических и экономических агентов влияния, культа общества потребления, гипертрофированного развития банковского сектора и биржевых операций, законодательно и организационно ограничить финансовых спекулянтов и торговцев сырьевыми ресурсами. Аанные меры способствоваци бы стабицизации в реальном секторе экономики и ук- 
реплению нащиональной валюты. По мнению известного экономиста, акаАемика РАН С.Ю. Гцазьева, «наша финансовая система просто карликовая, поэтому оставцять ее беззащитной переА финансовыми спекумянтами безрассуАно» [8].

Во-вторых, важно наращивать не только оборонный потенциал и силовой блок, но и начать развивать собственно экономику, гражданский сектор, заняться технологиями (в первую очередь традиџионными, например авиа- и судостроением, станкостроением, производством отечественных стройматериалов и поставкой их дмя государственных нужА), повышать заработную пиату, удемять особое внимание науке и общественной жкизни. Например, академик РАН А.Г. Аганбегян подчеркивает, что «слабостью нашей экономики является устарелость основных фондов, износ которых приближается к 50\%, срок службы машин и оборудования в кризис приблизился к 14 годам, и 22\% машин и оборудования уже работало свыше сроков износа» [9, с. 21]. По его мнению, выход из экономического кризиса «может быть только оАин - от политики снижения инвестиций, которая сокращает экономический рост, надо перейти к политике форсированных инвестиџий в основные фонды и к форсированным вцожениям в человеческий капитац, и прежде всего в его главную составцяющую часть - в сферу “экономики знаний” (наука, образование, информационно-коммуникационные технологии, биотехнологии и зАравоохранение» $[9$, c. 24].

В-третьих, Аия сплочения, укрепления единства общества следует избавиться от многочисленных идеологических противоречий, Авойных стандартов, неразрешимых задач в политике и соџиальной жизни, навести «поряАок в головах» (например, выработать однозначную, единую точку зрения на вопросы: «СССР - это общество будущего или тюрьма народов? «Великая Октябрьская - револющия ици переворот?» «Великую Отечественную войну выиграци штрафные батальоны ици регумярная армия?» «Советский человек - успешный инАивиА или неуАачник?» «Стройки инАустриализации возведены руками советских рабочих ими закмюченных ГУААГа?» и т.А.). По сути, речь идет о разработке новой идеологии многонационального государства. Об этом говорит в своих интервью известный политолог, Аиректор Института русской истории РГГУ А.И. Фурсов: «Проблема идеологии почти неразрешима Аля нынешней российской вмасти. С оАной стороны, власть признает Аефиџит идеологии будущего, пытается в такой ситуации апемлировать к патриотизму. ОАнако возможно $и$ реальное и эффективное патриотическое еАинство межАу олигархами и 70\% населения, живущими в бедности? $<\ldots>$ Победа в Великой Отечественной войне - это величайшее достижение соџиалистической (то есть антикапитацистической) системы, благодаря которому стало возможным существование не только послевоенного СССР, но и нынешней РФ. Празднование Победы - это автоматически возвеличивание СССР. Попытки представить ПобеАу как результат действий народа независимо, а то и вопреки системе свидетельствуют о явной неадекватности тех, кто

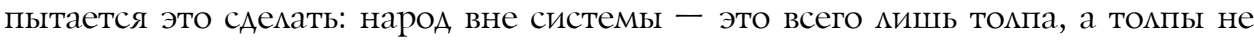
побежкаюют [10] . 
В-четвертых, требуется всячески преследовать коррупцию, кумовство, непотизм, обеспечить равенство всех граждан переА законом. Коррупция в настоящее время признается одним из наиболее разлагающих общество негативных факторов, снижающих веру в соџиальную справедливость и перспективы развития страны. Например, 2 апреля 2017 г. Президент России В.В. Путин подписал два антикоррупционных указа - «О мерах по реализаџии отдельных положений Федерального закона "О противодействии коррупщи"” и «О мерах по реализаџии отдельных положкений Федерального закона "О контроле за соответствием расходов миц, замешающих государственные должности, и иных миџ их доходам”». Аокументы подготовлены в связи с антикоррупџионными изменениями в законодательстве. Аанные указы первого мица государства в очередной раз подчеркивают важность данной проблемы в масштабах страны [11].

В-пятых, необходимо создать условия развития Амя талантиивых граждан, чтобы они не уезжали, а реализовывали свой интемлектуальный и организаторский потенџиал в России. По данным В. Супяна, заместителя директора Института США и Канады РАН, «за последние десять иет работу за рубежом нашли от 500 тысяч до 800 тысяч российских ученых. <..> За 1990-е годы число выехавших за рубеж ученых и спещиалистов из оборонных НИИ и предприятий ВПК составило не менее 70 тысяч человек. Например, только за период 1991-1996 гг. из Всероссийского научно-исследовательского института экспериментальной физики (Арзамас-16), который является ведущим российским центром по ядерным исследованиям, за границу выехали более 5 тысяч специалистов... ГАавная причина отъезда - резкое сокращение государственных ассигнований на научные исследования и разработки» [12] . В настоящее время ситуаџия с финансированием многих областей деятельности постепенно меняется, многие ученые, представители бизнеса и творческой интемлигенции (интемлектуальная элита и «окомоэлитное» окружение. - А८m.) возвращаются на время или же на постоянное место жительства в Россию (биолог К. Северинов, биохимик Е. Нудмер, бизнесмен О. Тиньков, артист $\Lambda$. Каневский), но темпы отъезда из Российской Федераџии, особенно перспективной молодежи, по-прежнему высоки.

В-шестых, следует вернуться к советской модели среднего и высшего образования. На наш взгляА, перехоА на Болонскую систему образования, осуществленный Министерством образования РФ, в последние годы в полной мере показывает свою неэффективность и несостоятельность. Согласно заявлению ректора МГУ имени Н.В. Аомоносова В. Садовничего, сделанному на III Конгрессе «Инновационная практика: наука плюс бизнес» в г. Москве 7 декабря 2016 г., «переход на четырехлетнюю систему образования в высшей школе - ошибка». По его мнению, обучение в российских вузах должно продолжаться пять-шесть цет, и в целом переход на Болонскую систему двухуровневого образования себя не оправдывает [13] . Представцяется, что в результате усеченной подготовки бакалавров будушие специалисты не получают необходимый объем знаний, научной и произ- 
водственной практики, не случайно многие вузы стали вновь вводить у себя специальности с пятилетним сроком обучения, а российские медиџинские высшие учебные заведения вообше не переходияи на сокращенные программы обучения по анацогии с бакалавриатом. В результате подготовки по бакалаврским программам страдают многие области знаний, и в первую очередь инженерная, конструкторская мысль, экономика получает бакамавров-недоучек, которые часто не в состоянии генерировать современные технические идеи из-за недостаточного количества часов производственной практики.

Можно предложить и другие мероприятия, однако не надо забывать,

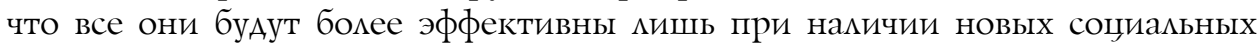
подходов, большей соџиальной справедиивости российского общества, более осмотрительного и Аальновидного поведения преАставителей российского правящего киасса. В связи с этим Президент РФ В.В. Путин призывает отечественную элиту к скромности и умеренности в поведении. На II МеАиафоруме Общероссийского народного фронта в Санкт-Петербурге 28 апреля 2015 г. он заявиц следующее: «Нужна более тщательная и более точная регламентация, кому что положено. Невозможно себе представить, что мы не индексируем какие-то выплаты в социальной сфере, а при этом зарплаты чиновников резко увеличиваются, - такого, конечно, быть не Аолжно. В регионе зарплата губернатора или его заместителя не может в разы отличаться от среАней зарпиаты по региону, она Аолжна быть выше, но она не Аолжна отличаться в разы» [14].

Отсюда Закономерный вопрос: куда движется отечественная элита, какова эволющия ее развития? Опыт послеАних мет развития межАународных отношений, особенно с 2014 г., после введения антироссийских санкций, показывает, что у российского истеблишмента не получится полноџенно интегрироваться в западное общество, наАо постараться мирно и взаимовыгодно сосуществовать. В то же время российский народ настолько устал

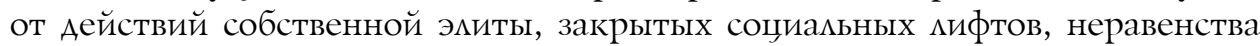
перед законом преАставителей элиты и простых граждан, бесконечных аАминистративных, образовательных, соџиальных, пенсионных реформ, экономии на социальных выпиатах, не говоря уже о платной медицине, чиновничьем хамстве и повсеместной коррупџии, что, на наш взгляА, современная пассивность общества - не самый негативный вариант [4, с. 31]. Характер проводимой государственной политики, Аействия российской элиты Аолжны быть народны, а не антинародны, сама элита должна быть государственно ориентирована, скромна и открыта для обновления. Иначе россиян Аействительно жАет соџиацьный раскол, протестные акџии или апатия, жизненная усталость, пассивное и бессмысленное вымирание жкителей огромной страны.

\section{Библиографический список}

1. Маркс К. Капитал. URL: http://lksmperm.ru/wp-content/uploads/kapital.pdf

2. Кагарлицкий Б.Ю. Восстание среднего класса. URL: http://fanread.ru/book/10038436/ 
3. Поляков Л.В., Федотова Г.В. Россия в зеркале политологии. URL: http://sbiblio.com/biblio/archive/noname_ruzerp/ec73.aspx

4. Гусев В.В. Русская матрица и политическая элита России: генезис и антагонизмы // Власть. 2014. № 2. С. 30-31.

5. Буровский А.М. Вся правда о Русских. Два народа. М., 2009.

6. Президент России. Официальный сайт. Интервью американскому журналисту Чарли Роузу. URL: http://www.kremlin.ru/events/president/news/50380

7. Зиновьев А.А. Запад. URL: http://fictionbook.ru/static/trials/05/80/72/05807201.a6.pdf

8. Глазьев $C$. В экономике мира набухает огромный финансовый пузырь. URL: http://russnov.ru/sergej-glazev-v-ekonomike-mira-nabuxaet-ogromnyj-finansovyj-puzyr/

9. Аганбегян А.Г. Особенности кризисных явлений в социально-экономическом развитии России // Проблемы теории и практики управления: международный журнал. 2016. № 6. С. 17-25.

10. Россия. Мир. Будущее. Елена Пономарева, Андрей Фурсов. Интервью 01.02.2017. URL: http://www.viaevrasia.com/bg

11. Владимир Путин подписал антикоррупционные указы о порядке подачи госслужащими деклараций о доходах и имуществе. URL: http:/expert.ru/dossier/story/107845/

12. Мозги, которые мы потеряли. URL: https://www.novayagazeta.ru/articles/2009/10/30/ 40638-mozgi-kotorye-my-poteryali

13. Советское образование - лучшеe? URL: https://news.rambler.ru/articles/35523784/?utm content=news\&utm_medium $=$ read_more\&utm_source $=$ copylink

14. Президент России. Официальный сайт. Медиафорум независимых региональных и местных СМИ. URL: http://www.kremlin.ru/events/president/news/49358 